\title{
HISTORIA: ¿EPISTEMOLOGÍA U ONTOLOGÍA? -DE LA CONTROVERSIA DE P. RICOEUR CON M. HEIDEGGER*-
}

\section{GERMÁN VARGAS GUILLÉN*}

La vida no es la que uno vivió, sino la que uno recuerda y cómo la recuerda para contarla (p. 7).

(...) Mi madre, petrificada en el umbral, exhaló una exclamación terminante: - ¿Ésta no es la casa!

Pero no dijo cuál, pues durante toda mi infancia la describían de tantos modos que eran por lo menos tres casas que cambiaban de forma y sentido, según quien las contara (p. 44).

(...) Los adultos lo embrollaban todo delante de mí para confundime, y nunca pude armar el acertijo completo porque cada quien, de ambos lados, colocaba las piezas a su modo (págs . 50-51).

G. García (Vivir para contarla).

Resumen: La exposición se desarrolla en cuatro parágrafos. En el primero se amplían las nociones heideggerianas presupuestas en el planteamiento de Paul Ricoeur dentro del ensayo La función narrativa y la experiencia del tiempo para cuestionar la pretendida corrección a la que apunta el mismo; en el segundo se establece un cotejo entre el título Dasein y el título subjetividad, apelando a la propuesta husserliana; en el tercero se caracteriza la noción narratividad en su relación funcional tendiente a crear una conciencia subjetiva de tiempo-histórico (la configuración); en el cuarto, y último, se valora el aporte de Ricoeur al despliegue de biografía e historia con la estructura de la narración.

Palabras clave: Dasein, intratemporalidad, ser-para-la-muerte, existencia, configuración, historia, acontecimiento, suceso, trama, narrativa.

Abstract: The lecture is developed in four paragraphs. In the first one, Heidegger's notions, presupposed in Paul Ricoeur's position inside the essay The narrative function and the experience of the time, are enlarged to question the sought correction to which it aims by itself. In the second one, a comparison is made between the title Dasein and the title subjectivity, appealing to Husserl's proposal. In the third one, the notion of narrativity is characterized in its functional relationship in order to create a subjective conscience of -historical time (the configuration). In the fourth one, and last, Ricoeur's contribution to the unfolding of biography and history with narration structure is valued.

Key words: Dasein, intratemporalidad, be-for-the-death, existence, configuration, history, event, succes, schemes, narrative.

El objetivo de esta exposición se orienta a la pregunta que la titula. No se trata, por tanto, de 'salvar' a Heidegger de la interpretación desarrollada por Ricoeur -lo

\footnotetext{
*P rofesor Asociado Universidad Pedagógica Nacional 
cual ni lo requiere el uno, ni le resta méritos al otro-. La cosa misma que sí está en discusión es si al tratar la historia, ella tiene que ser vista desde el punto del 'conocimiento histórico' o desde la búsqueda de una 'existencia auténtica del sujeto en la historia'.

Al fin y al cabo, los seres humanos son históricos, aunque no tengan un conocimiento disciplinar del devenir; no obstante, la existencia misma puede perder totalm ente su sentido, su autenticidad, si no se orienta históricamente; esto es, si no se realiza como una función enraizada en el sí mismo de cada quién que se relaciona con otros y que construye futuro. Por tanto, ser-histórico - en cuanto ser-humano- significa tener una estructura proyectiva como sujeto. Esta estructura no depende de la erudición histórica, pero vincula el haber-sido, el ser y el tener-que-ser. Que el ser lo sea en cuanto se orienta hacia la muerte puede indicar un télos inmanente a la conciencia; o, como se verá privilegiado aquí, puede significar que se requiere hacer explícito el límite dentro del cual se puede construir un sentido de ser, realizar una vocación, consolidar un proyecto. Lo que se encuentra enfrentado es la visión de la historia como suceso o como acontecimiento.

\section{La pretendida corrección de Ricoeur a Heidegger}

\section{Primariamente 'verdadero', es decir, descubridor, es el Dasein².}

En La función narrativa y la experiencia del tiempo ${ }^{3}$ Paul Ricoeur se propone relacionar las dos variables propuestas en el título. La narración es una de las modalidades del uso del discurso hemenéutico. Ricoeur se propone discutir y corregir a M. Heidegger; y, en particular, la función otorgada por éste al tiempo en cuanto ser-para-la-muerte. As í, Ricoeur supone una comprensión del Dasein que lo hace refutar la idea de historia, en cuanto enfocada hacia el futuro (FN\&EHT: 203), des de el carácter retrospectivo de la analítica del tiempo.

Comprender, pues, la propuesta de Ricoeur, exige volver sobre indicaciones centrales de Heidegger con las cuales caracteriza el Dasein. Acaso la propuesta de "corrección" de la doctrina heideggeriana, sugerida por Ricoeur, tenga dos escollos; uno, en el hecho de que la muerte no es un destino, sino más bien un límite; otro, en la idea de que Heidegger se propone una epistemología de la historia cuando su teoría se limita a describir el carácter existencial del devenir histórico.

\section{El Dasein es existencia}

Por su naturaleza, el Dasein es existente -el lugar [ente] donde el ser 'toma conciencia' de ser, o donde se sabe ser el ser-; esta 'toma de conciencia'

\footnotetext{
${ }^{2}$ Heidegger, Martin. Sein und Zeit.. Tübingen, Neomarius Verlag, 1949 (citado: SZ); p.220.

${ }^{3}$ Ricoeur, Paul. La funcion narrativa y la experiencia humana del tiempo. En: Historia y narratividad. Barcelona, Ed. Paidós, 1999; págs. 183 á 214 (en adelante citado: FN\&EHT). 
modaliza la condición de arrojado que le descubre su ser proyecto -su poder-ser, su querer-ser, su tener-que-ser- que sólo le es posible 'abrir' mediante el comprender en su darse-cuenta de que la muerte es un final o fin irredimible que lo descubre como ser histórico.

Para Heidegger, "la 'es encia' del Dasein consiste en su existencia" (SZ: 42) y "existir (ex-sistir) significa: estar sosteniéndose dentro de la nada". Para decirlo mediante una representación gráfica, se trata de vivir en el límite entre ser y nada, entre afimarse esencialmente o desaparecer en la aniquilación; y, sin embargo, como tal, la existencia impone un sobrenadar, un estar-por-encima de la nada; y, al tiem po, estar siempre rodeado o circundado de y por la nada.

Por esto mismo el Dasein "cada vez [es] su posibilidad (...) puede en su ser 'escogerse', ganarse a sí mismo, puede perderse" (SZ: 42). Sólo, entonces y por esta razón, el Dasein es el que experimenta la angustia; ésta a su turno le exige una vida atenta que impone el cuidado; as í "pertenece a la esencia de la persona existir solamente en la ejecución de actos intencionales; y así por esencia ella no es un objeto" (SZ: 48).

Mas, el Dasein es, al mismo tiempo, comprender y convi vir intersubjetivamente; está fuera de sus condiciones de posibilidad entenderse como ipse solus; por el contrario, todo su actuar está en-medio-de-los-otros y es tá proyectado hacia-ellos. Y, no obstante, actúa -tiene que actuar-como ab solutamente responsable de sí, de los otros y del mundo. En palabras del mismo Heidegger: "El mundo del Dasein es un mundo en lo común [Mitwelt]. El estar-en es un coestar con los otros. (...) Es la coexistencia” (SZ: 118); “(...) al ser del Dasein que a éste le va en su mismo ser, le pertenece el coestar con otros. Por consiguiente, como coestar el Dasein 'es' esencialmente por-mor-de otros. Esto debe entenderse como un enunciado existencial de esencia" (SZ: 123).

Sin embargo, Heidegger -por as í decirlo- elimina la noción de sujeto, es decir, no hay is omorfismo entre Dasein y sujeto; el primero es un quién y "el quién no es éste ni aquél, no es uno mismo, ni alguno, ni la suma de todos. El 'quién' es el impersonal, el 'se' o el uno [das Man]" (SZ: 126); el segundo, más bien, es protagonis ta, es persona, es personal, es 'éste' o 'aquél'. Tal vez la manera como se hace más visible la diferencia entre ambos es señalando que el sujeto tiene más que todo un carácter cognoscitivo mientras el Dasein tiene un carácter existencial.

La existencia no es un estado; es un proceso. El Dasein no es así e indefinidamente. Un juicio, en cambio, es un estado cognoscitivo, una vez proferido es así e indefinidamente; y, aún cuando el sujeto vive procesos cognoscitivos, éstos son más bien cambios de estado. El sentido de la existencia se da en un temple de ánimo, y siempre como tal; por ello no es un fin o un final, sino un momento del proceso. Cuando ese sentido existencial se detemina está

\footnotetext{
${ }^{4}$ Heidegger, Martin. ¿Qué es metafisica? Bs. As., Siglo Veinte, 1970; pág. 97.
} 
ya fuera de sí, es un éxtasis. Así, por el éxtasis, en su pura existenciaridad, el Dasein funda la temporalidad -que esta fundación sea auténtica o no, será el objeto mismo de la analítica existenciaria del Dasein-.

\section{El carácter de arrojado del Dasein}

(...) el Dasein esquiva, de un modo óntico-existentivo, el ser que ha sido abierto en el estado de ánimo; desde un punto de vista ontológico-existencial esto significa: en eso mismo a lo que semejante estado de ánimo se vuelve, se desvela el Dasein en su estar entregado al ahí. En el mismo esquivar está abierto el ahí.

Este carácter de ser del Dasein, oculto en su de-dónde, pero daramente abierto en sí mismo, es decir, en el 'que es', es lo que llamamos la condición de arrojado [Geworfenheit] de este ente en su ahí; de modo que el Dasein es el ahí (SZ: 145).

No hay un antes o un después del Dasein. Él es, puede decirse, un punto protofontanal: la fuente primera, primaria, del acontecer. Lo que ha sido, lo que es, lo que será (los éxtasis) dependen de un ahí donde el ser se sabe en despliegue; y este despliegue funda posibilidades frente a las cuales, ahí [Da], se tiene que tomar posiciones, decisiones, deteminaciones de ser [Sein].

Sin saberlo desde antes, sin un tiempo para saberlo después, ahí [Da], sin más, esto es, arrojado, deviene en existente. El carácter de arrojado es apertura que abre a las condiciones de posibilidad -afimándolas o negándolas-. No puede renunciar, a menos que se determine por la muerte como causa sui; pero ésta es la 'afirmación' de la nada, es pues su propia negación al 'afimarse aniquilándose' la que abre, a su turno, la posibilidad de no ser.

Estoy arrojado en el mundo, no en el sentido de quedame abandonado y pasivo en un universo hostil, sino, al contrario, en el sentido de que me encuentro solo y sin ayuda, comprometido en un mundo del que soy enteramente responsable, sin poder, haga lo que haga, arrancame ni un instante de esa responsabilidad, pues soy responsable hasta de mi propio deseo de rehuir de las responsabilidades; haceme pasivo en el mundo, negarme a actuar sobre las cosas y sobre los otros, es también elegirme, y el suicidio es un modo entre otros de ser-en-el-mundo. Con todo, me encuentro con una responsabilidad absoluta ${ }^{5}$.

Si en la angustia lo que angustia es la nada, en el arrojamiento lo que angustia es la posibilidad en su inmensa apertura, es saber-se enfrentado a la urgencia de tener-se que decidir. En cierto modo, es la absoluta responsabilidad, en primera persona, por el destino del ser. Y, como fundamento de la angustia, es la toma de conciencia de una absoluta responsabilidad no elegida que, sin embargo, no da otra posibilidad que la de la elección. Sartre llamó a esto la condena a la libertad (ob. cit.).

El Dasein, es, por tanto, el ahí de la condición de arrojado; así mismo, es la toma de conciencia de las posibilidades ante las que él mismo es y se hace libre; $\mathrm{y}$, por ello, se hace responsable del destino del mundo. Por esta condición, de

\footnotetext{
${ }^{5}$ Sartre, Jean Paul. El ser y la nada. Ensayo de una ontología fenomenológica. Barcelona, Eds. Altaya, $1993 ;$ pág. 578. Universidad Pedagógica Nacional
} 
manera simultánea, se libera de la sujeción óntica, es decir, deja de ser un 'ente encadenado' y se 'autoencadena' en su horizonte de realización.

Por tanto, ahí [Da], en otros términos arrojado, es liberación y servidumbre del destino del ser. Queda, para meditarlo, el verso de Lezama Lima: “¿Por qué los griegos, paseantes muy sensatos, / nos legaron el ser? Otra guarida enfrente , / otra guarida lame como lobo a su noche. / La chispa fue robada ¿por qué en nosotros el ser? / y en su huída los dioses nos dejaron el ser",

\section{La pura exis tenciaridad del Dasein es proyecto}

Si bien lo-sido se da, como tal, en cuanto expresión del ser en su actualidad, loque-será revela -igualmente- las actuaciones (actualizaciones) posibles-de-ser. Lo yecto indica lo lanzado hacia... e igualmente el carácter del ser-arrojado. La estructura proyectual del Dasein revela que el presente es una realización de los proyectos intencionados en diversos momentos del pasado; así mismo, revela el ser-horizonte del Dasein en el presente como ser-hacia...; mas, el presente mismo es proyección tanto del pasado en el presente-viviente como del presente-viviente en su estructura intencional de llegar-a-ser...

Pura existenciaridad indica que al ahí del ser [Dasein] no le es indiferente o inútil la estructura proyectual. Al contrario, revela que sólo a partir de ésta se da sentido a sí mismo el Dasein y, por ello mismo, comprende.

(...) el comprender tiene en sí mismo la estructura existencial de lo que nosotros llamamos el proyecto. Con igual originariedad, el comprender proyecta el ser del Dasein hacia el por-mor-de y hacia la significatividad en cuanto mundaneidad de su mundo. El carácter proyectivo del comprender constituye la aperturidad del ahí del estar-en-el-mundo como el ahí de un poder-ser. El proyecto es la estructura existencial de ser del ámbito en que se mueve el poder-ser fáctico. $Y$ en cuanto arrojado, el Dasein lo está en el modo de ser del proyectar. (...) en cuanto Dasein, el Dasein ya siempre se ha proyectado, y es proyectante mientras existe. El Dasein, mientras es, ya se ha comprendido y se sigue comprendiendo desde posibilidades. El carácter proyectivo del comprender implica, además, que el comprender no capta lo que él proyecta -las posibilidades en forma temática. (...) El proyecto, en el proyectar mismo, pro-yecta ante sí la posibilidad en cuanto posibilidad y la hace ser tal. El comprender, en cuanto proyectar, es el modo de ser del Dasein en el que éste es sus posibilidades en cuanto posibilidades (SZ: 145).

Y, como queda dicho, no es un comprender teórico, ni teorizante. Es pura existenciaridad, es decir, se trata del poder-ser que se halla presente en todo ahora, protoimpulsivamente, antes de que se eleve a la categoría de ser temático o de estar expuesto ante la estructura cognoscitiva del sujeto. El carácter, pues, de proyecto indica un todavía-no que pulsa por llegar a ser. Es, en todo caso, intencionalidad que compromete todas las potencias anímicas, también las cognoscitivas; pero igualmente, las volitivas, las afectivas, las imaginativas.

${ }^{6}$ Lezama Lima, José. Danza de la jerigonza. En: La fijeza. Poesía Completa. Madrid, Aguilar Eds., 1988 T. I, pág. 220. 
Estructura proyectual y voluntad de poderío -en el sentido nietzscheano- se corres ponden mutuam ente, coexisten; $y$, sin embargo, ninguna antecede a la otra. Al contrario, su mutua correspondencia y coexis tencia hace que el sentido sólo se pueda comprender extáticamente.

Si el Dasein mismo no se 'autocomprendiera' como una potencia-realizativa, como la fuente de sentido desde la cual adquieren 'orden' y 'destino' las posibilidades, entonces no tendría más horizonte que el ser-deteminado-por otras estructuras de ser; pero el Dasein toma conciencia de su ser comprendiéndo-se.

El Dasein en cuanto comprender proyecta su ser hacia posibilidades. (...) A este desarrollo del comprender lo llamamos interpretación (...) La interpretación (...) consiste en (...) la elaboración de las posibilidades en el comprender (SZ: 148).

Aquí, pues, es cuando Heidegger equipara comprender e interpretar. Acaso esto sea algo que puede ser equiparado con el concepto de configuración desarrollado por $\mathrm{P}$. Ricoeur. Sin embargo, se deben elucidar estos términos sin un recurso, por ahora, a es te último autor. Para Heidegger mismo, la comprensión anticipa sentidos de las posibles direcciones de ser; la interpretación hace venir al presente el presente-sido [pasado] que en su intención realizada aparece como actualidad.

El ser-proyecto que le concierne al Dasein se realiza por la dialéctica entre comprender e interpretar.

\section{Comprender-se como lo propio del Dasein}

Como queda visto, no se trata de una hermenéutica del sujeto, sino de una hermenéutica existenciaria o, lo que es lo mismo, de una hermenéutica del Dasein. Abriéndose al mundo del sentido, el Dasein constituye [que no construye] el sentido del mundo por darse sentido a sí mismo como existente. Mas, es to lo hace cada Dasein, que en cada caso soy yo mismo, todo el que puede decir yo en la autenticidad de su existencia [mismidad].

Heidegger observa, en este respecto:

El Dasein es un ente que en su ser se comporta comprensivamente respecto de este ser. (...) El Dasein existe. El Dasein es (...) el ente que cada vez soy yo mismo" (SZ: 53). El conocimiento es una modalidad de ser del Dasein en cuanto estar-en-elmundo, esto es, que tiene su fundamento óntico en esta constitución de ser (SZ: 81).

(...) el comprender (...) tiene la estructura del proyectar (SZ: 311-312).

Ahora bien, todo el comprender ocurre en la experiencia del habla, en la forma como el yo discurre sobre el mundo, al fundarlo, dándole sentido. Queda, entonces, constituida la esfera del discurso como aquella en la que se otorga sentido al mundo desde el Dasein que en su pura existenciaridad requiere abrir mundo. Heidegger lo indica cuando señala que: “(..) a la aperturidad del Dasein le pertenece esencialmente el discurso" (SZ: 223). "El discurso [Rede] es existencialmente cooriginario con la disposición afectiva del comprender" (SZ: 
161); y, sin embargo, "Para poder callar, el Dasein debe tener algo que decir (...). El silencio manifiesta algo y acalla la "habladuría" (SZ: 165). "Quien callando quiere dar a entender algo, ha de 'tener algo que decir" (SZ: 296).

Comprender y aprehender son dos dimensiones del mismo acto, a saber, del discurrir. Cuando en su existenciaridad el Dasein comprende, es porque ha otorgado sentido al mundo; y al hacerlo se ha aprendido a sí mismo constitutivamente como yo [yo-polo, yo-centro, yo-mismo], que, en fin de cuentas, deviene como yo-proyecto.

Comprender, interpretar, discurrir y callar son parte del proyectar. Quedan, junto a los predicados que le pueden convenir al discurso, las voces del silencio: el yo-cuerpo que anónimamente se da a entender a los otros, se aprehende a sí mismo en sus posibilidades existenciales, se manifiesta en la intimidad, es decir, es el existente mismo que carece o no requiere de las palabras para que, creando lenguaje, abra mundo y constituya el sentido de la experiencia de ser.

(...) Comprender (...) significa (...) comprenderse a sí mismo en el poder-ser que se desvela en el proyecto ( $S Z$ : 263). Libre para las posibilidades más propias, determinadas desde el fin, es decir, comprendidas como finitas, el Dasein conjura el peligro de desconocer, en virtud de su comprensión finita de la existencia, las posibilidades de la existencia de los otros que lo superan, o bien de forzarlas, malinterpretándolas, a entrar en la existencia propia -renunciando así a la más propia existencia fáctica (SZ: 264).

La comprensión, radicalmente, es la actividad que revela al Dasein la finitud. Y dado que ésta se presenta como el principio según el cual todo tiene un final, o, en otros térm inos, todo llega a su fin, comprender es el aprehender-se del Dasein, es su darse cuenta de que "todo pasa y todo queda". Entonces, queda el horizonte del ahí: se trata de apoderarse de las posibilidades, pero sin negar que algunas de ellas corresponden a los otros; que otras cuantas pueden ser corealizadas por el yo -en primera persona: por el yo que soy yo- en la mutua relación con otros, que posibilitan tanto al alter como al yo.

La historia es propiedad ontológica del Dasein

El 'fin' del estar-en-el-mundo es la muerte [Das 'Ende' des In-der-Welt-seins ist der Tod]. Este fin, perteneciente al poder-ser, es decir, a la existencia, limita y determina la integridad cada vez posible del Dasein. El haber-llegado-a-fin del Dasein en la muerte y, por consiguiente, el estar-entero de este ente, sólo podrá empero ser incorporado en forma fenoménicamente adecuada al examen del posible estar-entero cuando se haya logrado un concepto ontológicamente suficiente, esto es, un concepto existencial, de la muerte (SZ: 234).

Para Heidegger la biografía del Dasein, de cada Dasein, tiene un fin, un término, un momento en que la existencia-no-va-más. Ese momento no se puede entender como un destino fatal -que, según la expresión de R. Darío consistiría en: "ir con fatales pasos, hacia el fatal abismo"-, ciego. Tan sólo se constata que en esa confrontación ser-nada hay un momento en que cada Dasein -como en el 
verso de L. de Greiff- tiene que declarar: "la llevo perdida". Al final, no es que la muerte puede más, sino que por plena y en la plenitud misma de la vida: se agotan todas las posibilidades de ser.

La muerte, como principio ontológico, mues tra la inminencia del detenerse de la existencia. Ella no es un postulado epistemológico, no trata de fundamentar el sentido del giro hemenéutico. Ella le compete al Dasein; por ella el Dasein se sabe situado frente a sus posibilidades, finitas, de realizar, de llenar de contenido, sus proyectos.

Precisamente, porque el Dasein es ser-para-la-muerte, y porque la muerte es un principio ontológico, la noción heideggeriana de la historia es, a su vez, estudiada ontológicamente. No se trata de ver cómo se construye el conocimiento histórico, sino cómo realiza su-ser-histórico el Dasein; es decir, cómo logra el Dasein el paso de la habladuría a la autenticidad histórica ${ }^{7}$.

“(...) El Dasein, en el fondo de su ser, es y puede ser histórico, y por qué puede, en cuanto histórico, desarrollar un saber histórico" (SZ: 255). La muerte sólo alcanza su "integridad" en el darse de la muerte; o en otros términos, es la muerte la que completa íntegramente el ser del ente del Dasein (SZ: 236); por eso la muerte no se experimenta como pérdida, sino que es pérdida para los que quedan (SZ: 239) y, en ese sentido, el morir es algo que debe asumir cada Dasein por sí mismo (SZ: 240). Así mientras está vivo, a cada Dasein le corresponde comprenderse como ein Noch-nicht (un todavía-no) (SZ: 242). "La muerte se revela así como la posibilidad más propia, irrespectiva e insuperable" (SZ: 250251). "El estar vuelto hacia la muerte se funda en el cuidado" (SZ: 259).

Para Heidegger: "Futuro' (...) mienta la venida en la que el Dasein viene hacia sí mismo en su más propio poder" (SZ: 325). "Futuro, haber-sido, presente, muestran los caracteres fenoménicos del 'hacia-sí' ['Auf-sich-zu', del 'de-vuelta-a' ['Zurück auf] y del 'hacer-comparecer-algo' ['Begegnenlassen von']. Los fenómenos del 'hacia...', del 'a...', del 'en medio de...' manifiestan la temporeidad

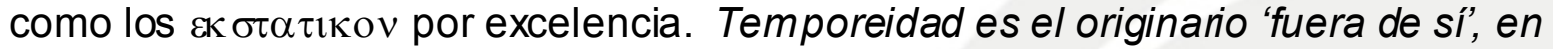
y por sí mismo" (SZ: 328-329). "La proposición 'el Dasein es histórico' [geschichtlich] se acredita como un enunciado ontológico-existencial fundamental” (SZ: 332).

Ricoeur considera que la postura de Heidegger se encamina en pro de una 'epistemología de la historia'. Como quedó probado, para Heidegger el problema es meramente existencial. Se comprende, entonces, por qué "no se le ocurrió a Heidegger es tudiar el estrato narrativo de la his toria" (FN\&EHT: 202).

\footnotetext{
7 “ Entelquia es el ser como término quieto, estadizo, del movimiento que lo ha producido: telos es la meta. Energía (dynamis), en cambio, es el movimiento que en sí mismo no tiene más remedio que recomenzar".

Ortega y Gasset, J. Historia como sistema. Madrid, Revista de Occidente, Col El Arquero, 1970; p. 137. 


\section{Sujeto vs. Dasein.}

el mismo Yo que es ahora actualmente presente, es en cierto modo en todo pasado, que es su pasado, otro Yo, precisamente aquel que fue y que ahora no es así; y, sin embargo, en la continuidad de su tiempo es el uno y el mismo Yo que es y fue y que tiene su futuro ante sí. En tanto que sometido al tiempo, el Yo actual de ahora puede tener relaciones con su Yo pasado y precisamente ya no de ahora, puede mantener un diálogo œn él y criticarlo como si fuera otro.

Ahora bien, todo se complica tan pronto como nos hacemos cargo de que la subjetividad sólo en intersubjetividad es lo que es: Yo que actúa constitutivamente. (...) En cierto modo, esto es de nuevo una temporalización, a saber: la temporalización de la simultaneidad de los polos-Yo (...).

Hua. VI, §50: 175

La exposición precedente permitió probar que el Dasein es existencia. Se insinuó que la subjetividad, el ser sujeto, en cambio, es posición cognoscitiva. De hecho P. Ricoeur (p. 151) ha asumido la noción de sujeto que propuso Husserl como Paarung en el § 44 de la Quinta Meditación Cartesiana (Hua. I). Esta noción implica reducir la experiencia del otro, o del extraño, a la esfera de propiedad. Es un intento de "salvar" la inters ubjetividad des de la subjetividad.

Mas, Huss erl mismo llegó a ideas diferentes de subjetividad e intersubjetividad, al pensarlas desde la perspectiva del tiempo. Aun en la esfera de propiedad como la llamara en Meditaciones Cartesianas, $\$ 44$ (Hua. I)- se ve que si se introduce la variable 'tiempo', todo cambia; el yo actual se comunica con el pasado yo; el yo actual intenciona su futuro yo.

Sin embargo, la variable 'tiempo' afecta estructuralmente al yo cuando se piensa en relación con el tú; es decir, cuando se advierte que la subjetividad sólo es lo que es en intersubjetividad. Utilizando la terminología de Ricoeur, el yo es narrado por sí mismo, cuando hace una relación de su pasado yo, cuando se abre a comprender el horizonte histórico que le compete (como facticidad, como posibilidad); es narrado, por otro(s) cuando queda incluido en la constitución de sentido que abre -necesariamente- un horizonte compartido que hace las veces de suelo común.

Ahora bien, ¿qué va del diálogo a la narración? Para Husserl la categoría fundante de la intersubjetividad es el diálogo; para Ricoeur la categoría fundante de la historia es la narración. El diálogo deshegemoniza la palabra usada en primera persona, democratiza el uso de la palabra. La narración, en cambio, mantiene un protagonista, un lugar del habla.

El Dasein se mueve por categorías como: comprensión, entendimiento, discurso (discurrir), hemenéutica y silencio. El sujeto, en cambio, por categorías como diálogo y narración. En todo caso, el sujeto se halla en las márgenes del lógos. En un caso, está presupuesta la inclusión del otro (diálogo); en el otro, la autocomprensión histórica. 
Consciente o no, Ricoeur se apunta a la idea de la subjetividad clausurada solipsistamente. En la narración se autocomprende quien narra. La voz del otro tiene que ser reducida a la del narrador para formar parte de la expresión que se contiene en sus fórmulas. Se trata, para decirlo en resumen, de la subjetividad del camino cartesiano, sin avanzar hasta el camino fenomenológico del mundo de la vida.

Es hora, pues, de sintetizar el punto en controversia. Cuando Ricoeur se da a la tarea de corregir el proyecto heideggeriano de la his toria entendida como serpara-la-muerte, desconoce que Heidegger mismo no tiene interés en una epistemología de la historia (así se pueda situar un debate con W. Dilthey; y otro con el Conde de York). En la medida en que la propuesta de Ricoeur es epistemológica, tiene que determinar la función del sujeto al construir conocimiento histórico; en este camino se detiene en la concepción fenomenológica, no obstante sólo estudia la doctrina del llamado solipsismo trascendental, sin dar el paso a la intersubjetividad como estructura constituyente del mundo de la vida.

\section{La configuración}

Desde el punto de vista epistemológico hay un problema que tiene que ser tematizado, a saber, la estructura teleológica. Ésta opera con injerencia tanto para la narración histórica como para la de ficción. Al parecer, comprender una 'his toria' implica es tar en algún punto de llegada des de donde se pueda saber qué era lo que todavía sin palabras se estaba poniendo en curso, cómo se llevaron a cabo variaciones -idas y venidas- en los 'acontecimientos' y su sentido hasta legar una manifestación his tórica definida.

A esta comprensión, a partir del punto de llegada, es a lo que P. Ricoeur ha denominado configuración:

(...) La disposición configurativa œnvierte la serie de los acontecimientos en una totalidad significativa que depende del hecho de 'considerar conjuntamente'. Gracias a éste, toda la trama puede considerarse con un solo pensamiento. (...)

(...) La configuración de la trama nos permite retomar y comprender la serie de acontecimientos a partir del final de la historia (...).

(...) Esta recuperación del sentido a partir del final aproxima la intelección de la trama a la idea de 'repetición', que, (...) es la clave de la verdadera 'historicidad'. (...) Se trata (...) de la (...) recapitulación de los episodios desde el punto de vista de la condusión (FN\&EHT: 198).

La trama tiene la propiedad de mantener la tensión que se requiere en la fenomenología tanto del acto de contar como de entender o seguir una historia (FN\&EHT: 192); pero "el 'final' de la historia es el polo de atracción de todo el proceso" (Íd). 
En cierto modo, la configuración impone la siguiente forma de comprender la fenomenología del proceso narrativo: desde la figura del final, esto es, desde el télos inmanente a la narración, se puede construir el despliegue de los episodios; en fin, la manera de superar la visión episódica de los 'hechos'-que de por sí no requieren conexión o que, si la tienen, no da una unidad de referencia- es introduciendo el componente del fin.

Ahora bien, ¿por qué se aparta de la propuesta heideggeriana? Baste con la siguiente observación: mientras Ricoeur le da al título fin una estructura teleológica, Heidegger se limita a tomar la noción en un sentido estrictamente ontológico -y aun, puede decirse, óntico-: el Dasein -quien es histórico y, por ello mismo, en su autenticidad, hace la historia- tiene un fin, es finito, acaba.

En la perspectiva de Ricoeur se tiene fin, que en cuanto télos, supone un inicio -que si no de los hechos, sí de la narración-. La trama es un enlace entrambos (inicio y fin; o, fin e inicio). De este modo, se pierde la posibilidad de que el tiempo vulgar -el del reloj, que representa la salida y la puesta del sol; el comienzo y el final del año- sea superado; precisamente, por su respeto a la trama con su función copulativa, no se supera la intratemporalidad.

La apuesta de Ricoeur por la configuración es un respeto indeclinable por la intratemporalidad que impide hallar nuevas vertientes -variaciones, se llamarán en clave fenomenológica- del haber-sido. El horizonte de pasado es así, indefectiblemente, para quien lo ha vivido; y más aún para quien lo ha narrado de una forma determinada.

Al lado de la crítica esbozada sobre la noción de sujeto, no obstante la completa obra del mismo Ricoeur titulada Freud: una interpretación de la cultura (México, Siglo XXI Eds., 1987; 483 págs.), queda igualmente la pregunta por el sentido de la configuración una vez puestos en la línea de la recuperación liberadora del pasado.

\section{Biografía e historia, un aporte}

Ahora bien, la recuperación del sujeto es, en todo caso, la vuelta sobre el sentido biográfico, la sintonía de las potencias anímicas con el yo que se sabe protagonista de la historia. Así, pues, quedan dos polos que fenomenológicamente se correlacionan: quién narra (polo noético) y qué se narra (polo noemático).

Si bien no es posible cerrar las puertas a la subjetividad -bajo ningún título-; la historia, el sentido com unitario del acontecer, funda las posibilidades de ser sujeto en cada condición cultural deteminada.

El ir y venir de sujeto a colectivo; y, al revés, de colectivo a sujeto, funda una propuesta que hace que sin la noción del "mártir" -aunque acaso sí con la del 
'héroe'- se vaya proyectando en medio de circunstancias (acontecimientos) la constitución personal del sentido de la vida, que se vive con los otros, en medio de ellos. Asu vez, si bien puede decirse con el dictum platónico que "las mayorías no piensan", es cierto que se tiene un ámbito referencial en el que se presentan las condiciones de posibilidad de realización de la existencia en la que cada cual que llega a comprenderse como sujeto.

La propues ta de Ricoeur abre un horizonte: configurar lo memorable (FN\&EHT: 210-211): ¿desde el punto de vista de quién?, ¿destacado de que 'materialidad histórica? Quizá des de nosotros mismos, en cada caso; tomando como referente para la comunicación a los vivos, a los antecesores y sucesores (FN\&EHT: 212); a todos ellos como si (en el sentido del analogon husserliano de Meditaciones Cartesianas, Hua. I) fueran, pudieran ser, tuvieran que ser: nuestros contemporáneos.

Cabe, en todo caso, la pregunta: ¿qué es un hecho?, ¿qué un suceso?

Por cierto, el "Descubrimiento" de América es un suceso; puede ser datado, se pueden explicitar sus 'causas próximas' y 'remotas', se puede hacer un listado de los protagonis tas, etc.; un acontecimiento, en cambio, no tiene que precisar con tal detalle los hechos, basta con que pueda ser descrito desde el punto de vista subjetivo.

En la fenomenología de poder seguir una historia se revela lo que tiene sentido para uno, desde uno. A modo de ejemplo hago la siguiente descripción: cuando era niño, tendría entre tres y cinco años, por mi pueblo natal recorría un loco, sobre el mediodía, las calles. Yo lo veía del tamaño de un gigante, atlético -diría hoy- y tostado por el sol, de pelo rizado, con una voz de trueno. A esa hora, tras el almuerzo, los niños debían hacer siesta. En medio de la somnolencia, oí los gritos del loco: “¡Fin del mundo, desaparición de la tierra, lloverá lenguas de fuego!". Ahora creo que es la primera vez que tuve una 'visión apocalíptica'. Cuando escucho ciertos discursos políticos -sobre la nación, sobre la universidad, sobre... - ya no tengo el terror de mi infancia; más bien, de un modo jocoso, razono para mí -a veces para mis contertulios- haciendo ver que se comunica o se tramita una 'visión apocalíptica'.

Con todo, esa vivencia tiene para mí el carácter de un acontecimiento. Sin embargo, ello no sucede como un fin o un final, según la orientación expuesta, sino como un dato que va y viene, que se reconstruye en su estructura de sentido; que retorna a una vivencia infantil, la reconstruye en el presente viviente, la actualiza según los intereses y la resignifica, según el darse del presente.

No obstante, la biografía tiene y puede tener un encuentro con la historia. Acaso sin el "Descubrimiento" no habría manera de que el loco de mi pueblo hubiese estado al corriente del texto que motiva la interpretación apocalíptica de la 
historia; acaso sin esa tradición cristiana de mi pueblo, no habría habido lugar para un acontecimiento como el referido, en mi vida.

Queda, as í, como un horizonte de investigación hemenéutica y fenomenológica el vínculo entre biografía e historia. Acaso éste sólo se pueda realizar desde el punto de vista de la narración. La historia siempre tendrá que ser contada desde el punto de vista de los sujetos que la experimentan y la biografía siempre tendrá que ser comprendida des de el contexto en el cual se realiza el sujeto como tal.

\section{BIBLIOGRAFIA CITADA}

FI EI DEGGER, Martín. ¿Qué es metafisica? Traducción de Xavier Zubiri. Buenos Aires, Siglo Veinte, 1970; 112 pp.

HEIDEGGER, Martín. Sein und Zeit. Tübingen, Neomarius Verlag, 1949. s. 438; se cita según la traducción Jorge Eduardo Rivera: Ser y tiempo. Santiago, 1998; 497 pp.

LEZAMA LIMA, José. Poesía Comp/eta. Madrid, Aguilar 1988; T. 1., 423 pp.

ORTEGA Y GASSET; José. Historia como sistema. Madrid, Revis ta de Occidente, 1970; 156 pp.

RICOEUR, Paul. Historia y narratividad. Traducción de Gabriel Aranzueque. Barcelona, Paidós, 1999; 230 pp.

SARTRE, Jean Paul. El ser y la nada. Ensayo de una ontología fenomenológica. Traducción de Juan Valrnar. Barcelona, Altaya, 1993; 648 pp. 